\title{
Literatura infantil fractal e mercado editorial: lições contemporâneas
}

\author{
Fúlvio de Oliveira Saraiva \\ Universidade Federal do Ceará (Fortaleza, Brasil)
}

Fernanda Maria Abreu Coutinho

Universidade Federal do Ceará (Fortaleza, Brasil)

\begin{abstract}
RESUMO: ESTE ARTIGO ANALISA IMPLICAÇÕES SOCIOLÓGICAS E FILOSÓFICAS DO CAMINHO QUE SE SEGUE AO OBJETO LITERÁRIO COMO MERCADORIA FETICHIZADA; CAMINHO DA DEFASAGEM DE VALORES QUE O REVESTIAM, A SABER, O VALOR DE USO, O DE TROCA E O DO PRÓPRIO SIGNO FETICHIZADO. ESTUDAREMOS O MOMENTO EM QUE A ARTE DEIXA DE BASTAR-SE A SI MESMA E PASSA A INTEGRAR A LÓGICA DE PRODUÇÃO ATUAL. REFLETIREMOS SOBRE O TEMA EM SUAS MUDANÇAS HISTÓRICAS, COMENTANDO OBRAS REPRESENTATIVAS E FUNDAMENTANDO NOSSA VISÃO SOBRE A RELAÇÃO MARKETING/IDEOLOGIA/LITERATURA INFANTIL.
\end{abstract}

ABSTRACT: THIS WORK ANALYZES THE SOCIOLOGICAL AND PHILOSOPHICAL IMPLICATIONS OF THE LITERARY OBJECT'S WAY AS COMMODITY FETISHIZED; WAY OF LAG OF VALUES, THE VALUE OF USE, THE EXCHANGE AND THE OWN SIGN FETISHIZED. WE WILL STUDY THE MOMENT IN WHICH THE ART IS NO LONGER SUFFICIENT TO ITSELF AND INTEGRATE THE LOGIC OF CURRENT PRODUCTION. WE WILL DISCUSS THE THEME IN IT'S HISTORICAL CHANGES, COMMENTING ON REPRESENTATIVE WORKS AND JUSTIFYING OUR VISION ON THE RELATIONSHIP MARKETING/IDEOLOGY/LTERATURE FOR CHILDREN.

PALAVRAS-CHAVE: CONTEMPORANEIDADE, CONSUMO, ESTUDOS CULTURAIS, LITERATURA INFANTIL, MERCADO EDITORIAL.

KEYWORDS: CONTEMPORANEITY, CONSUMPTION, CULTURAL STUDIES, LITERATURE FOR CHILDREN, EDITORIAL MARKET. 
literatura infantil diante de um novo reposicionamento dos signos (relacionado intimamente com a defasagem dos mesmos) não parece flutuar em um mar de conjeturas e especulações filosóficas vazio, mas sim, adaptar-se a uma lógica reinante que seleciona e dá circulação ao objeto literário. Essa lógica está presente em praticamente toda manifestação artística contemporânea da sociedade dita urbana pós-moderna ocidental. Portanto, como dado cultural que é, a literatura infantil é também, mas não somente, um reflexo das práticas sociais da sociedade produtora e reprodutora dessa lógica.

Assim, além do redimensionamento do objeto literário infantil e de seus signos preponderantes, temos em termos de análise, o problema da circunscrição do objeto científico como objeto de estudo. Já que as relações estabelecidas entre ele e a conjuntura mercadológica extrapolam o plano artístico, em nosso entendimento, faz-se necessária uma abordagem interdisciplinar que compreenda a obra literária infantil em sua virtual totalidade. O que por sua vez acarreta outro problema, a saber, o aparato teórico que excede a alçada da literatura.

O crescimento e a sustentabilidade da cultura de consumo têm no marketing, o fulcro da mídia, seu principal meio de comunicação de massa.

A maneira como a sociedade atual molda seus membros é ditada primeiro e acima de tudo pelo dever de desempenhar o papel de consumidor. A norma que nossa sociedade coloca para seus membros é a da capacidade e vontade de desempenhar esse papel (BAUMAN, 1999, p. 87-88).

Em "empatia" com a criança, a mídia sabe que atuar no espaço de independência infantil é um filão compensador. A noção de criança como um ser inocente e dependente do adulto foi abalada pelo domínio por parte das crianças no território da TV, cinema, games, música e internet. Intimamente ligada ao consumo dos livros de literatura infantil, temos a publicidade livresca que, no caso das crianças, atua principalmente junto às escolas em negociações administrativas e políticas. Dito isto, parece clara a necessidade de pesquisas sobre a relação entre a produção publicitária e a literatura, já que essa produção, além de intensa e ininterrupta, manipula, transforma, fomenta e adestra o consumo. 
Portanto, se objetivamos um entendimento interdisciplinar sobre a literatura infantil, devemos compreender e comprovar a influência que o marketing exerce sobre as crianças em suas aquisições.

[...] o publicitário aproxima seu conhecimento especialmente daquele dos psicólogos e sociólogos. A colocação da publicidade como próxima a estes campos de saber é uma das tônicas constantes no discurso dos informantes. Relacionam publicidade e psicologia porque acham que o anúncio mexe com a "cabeça das pessoas", atinge o "cérebro de cada um", toca a "mente do consumidor". Relacionam-se com a sociologia por acreditarem que a publicidade lida com a "massa", precisa conhecer as "nuanças do público" e perceber as "mudanças sociológicas" nos segmentos da população (ROCHA, 1995, p. 52).

Quando vemos a literatura infantil transfigurada em um valor fractal, que é a irradiação do signo por todas as direções possíveis e sem a referência primeira, temos o sentido original de seu surgimento desligado de sua própria existência. O objeto literário flutua aleatoriamente em uma trajetória particular (de partícula) desprovido de sua motivação literária, erra pelo cosmo disperso da irradiação produtiva. Vaga dentro de um sistema simbólico em que os signos, destituídos de seu significado imanente e incorporado, já não bastam para traduzirem-se efetivamente em um sentido imediato.

O que possibilita essa dispersão de sentido é justamente a abundância de produção e a saturação valorativa e contravalorativa que abastece a produção artística atual, fomentando ao mesmo tempo em que corrói a razão de ser de toda produção criativa.

No plano da literatura infantil, temos a superabundância de títulos, no mais das vezes de pouca expressão e baixo valor artístico, além da perda de valores referenciais, já que a superprodução acaba por eleger como best-sellers alguns títulos que nem sempre condizem internamente com sua qualidade atribuída externamente.

O que acontece quando a literatura infantil é cerceada pelo desligamento de sua origem, quando sua referência é responsável pelo seu próprio apagamento, quando sua existência remete a uma indiferença ao fazer literário, é o que interessa como motivo de reflexão deste trabalho. 
Nosso objetivo é analisar implicações sociológicas e filosóficas do caminho que se segue ao objeto literário como mercadoria fetichizada, tornando-se objeto de valor fractal.

Atentar ao que acontece com o consumo dos signos é uma tarefa obscura e exige mais do que aparelhagem teórica, exige intuição. O que pode resultar numa análise especulativa e subjetiva, e, ainda, contradiz seriamente os postulados da ciência - mas, como diz Baudrillard (2007), é uma questão de escolha.

Tomemos como exemplo o celular para ver o caminho que percorre o objeto até atingir seu valor fractal. Ao surgir era um objeto para poucos e sua tecnologia de ponta prometia total satisfação ao usuário. Nasceu com sua função bem definida: gerar e receber chamadas móveis com qualidade.

Essa função ainda era atribuída ao objeto e ele possuía os três estágios do valor:

I) o valor de uso - em que a função, utilidade, apreço, valor de custo, enfim, uma condição "natural" dá a valoração direta ao objeto pela relação que ele estabelece com o homem (a possibilidade de gerar e receber chamadas móveis); II) o valor de troca - a relação que se estabelece entre um referencial coletivo e o objeto, valorando-o (o dinheiro determina qual o valor referencial do celular, entrando ainda o valor de custo, e o valor de uso desemboca no valor de troca); III) o valor-signo - o valor referencial dentro de um sistema de valores, é um valor estrutural, ele corresponde a "um código, e o valor aí se desenvolve em referência a um conjunto de modelos" (BAUDRILLARD, 2008, p. 11).

Não se valora o objeto em si, mas o que ele representa dentro do conjunto, valora-se o seu signo (o celular como signo de modernidade e status, o carro como símbolo de poder, etc.). O valor-signo sobrepuja os outros.

O objeto pode até não mais servir para nada nem mesmo ter equivalência de valor de troca, mas o valor-signo acarreta-lhe valor na medida em que o redimensiona como signo dentro do conjunto.

Temos assim a trajetória convexa do celular revestida pelo processo da tecnologização, que é a distorção do uso da tecnologia em nome de uma lógica de produção descartável visando o giro de capital.

Hoje em dia, no Brasil, qualquer pessoa possui um celular e ele deve ser dos mais modernos, incorporando as funções secundárias. Quem não se rende a tal lógica sofre até discriminação. 
E esse ciclo se renova, pois logo surge um celular com uma nova função ou simplesmente lança-se um menor e todos passam a comprar celulares menores. Temos ainda o fetiche da mercadoria. Um objeto "obsoleto" só se torna obsoleto quando possuí-lo torna-se comum a todos. É preciso que surja outro objeto para suprir a carência de exclusividade da posse que se torna o fetiche da mercadoria e do consumo.

Com efeito, vemos o conceito de fetiche da mercadoria, de Marx, muito bem cristalizado nas práticas sociais. A análise do fetiche da mercadoria aponta para a alienação humana nas suas relações. Desde a Antiguidade a humanidade mantém-se ligada a relações fetichistas - seja com deuses, consanguinidade ou pelo valor-dinheiro - exprimindo formas diversas de relações inconscientes.

Concluímos que a função primeira do telefone celular - a capacidade de fazer e receber chamadas móveis, foi deixada em segundo plano. Ele foi destituído de sua função. E aí entramos no quarto estágio do valor, no seu valor fractal, filho do fetiche da mercadoria e irmão da tecnologização.

Quando as coisas, os signos, as ações são liberadas de sua ideia, de seu conceito, de sua essência, de seu valor, de sua referência, de sua origem e de sua finalidade, entram então numa auto-reprodução ao infinito. As coisas continuam a funcionar ao passo que a ideia delas já desapareceu há muito. Continuam a funcionar numa indiferença total a seu próprio conteúdo. E o paradoxo é que elas funcionam melhor ainda (BAUDRILLARD, 2008, p. 12).

Assim, o valor fractal, o quarto estágio do valor, é a defasagem dos valores que antes revestiam o objeto pela própria irradiação desenfreada do valor, que para Baudrillard, não se deveria nem chamar de valor pela impossibilidade de qualquer avaliação nesse contexto.

No quarto estádio, o estádio fractal, ou estádio viral, ou ainda estádio irradiado do valor, já não há nenhuma referência: o valor irradia em todas as direções, em todos os interstícios, sem referência ao que quer que seja, por pura contiguidade. No estádio fractal, já não há equivalência, nem natural nem geral, nem há lei do valor propriamente dita: só há uma espécie de epidemia do valor, de metástase geral do valor, de proliferação e dispersão aleatória. Em rigor, já não 
se deveria falar de valor, já que essa espécie de demultiplicação e de reação em cadeia torna impossível qualquer avaliação (BAUDRILLARD, 2008, p. 11-12).

\section{II}

Na década de 1960, não havia ainda o investimento privado pesado das editoras nas obras literárias infantis. Não havia, pois, um mercado profissional dedicado ao segmento como um setor autossustentável e reconhecido. Mas o mercado editorial já formava os alicerces que sustentariam o meio como um ramo rentável e formador de opinião.

Nesse contexto, Clarice Lispector surge como autora de literatura infantil e traz uma quebra de paradigma para o gênero. Aos olhos dos pequenos e sob a imagem deles, serão expostas situações de crueldade, de morte, de inveja, ira, separação sob a crença de que se pode falar sobre todo e qualquer tema com as crianças e sobre elas, dependendo de como se fala e dissolvendo a imagem estática de infância. Um exemplo dessa característica é $A$ mulher que matou os peixes (1968). A narradora assume o papel da causadora da morte dos peixes e joga com a relação entre o factual e o ficcional:

Essa mulher que matou os peixes, infelizmente, sou eu. Mas juro que foi sem querer. Logo eu! que não tenho coragem de matar uma coisa viva! Até deixo de matar uma barata ou outra (LISPECTOR, 1983, p. 7).

Antes de começar, quero que vocês saibam que meu nome é Clarice. E vocês, como se chamam? Digam baixinho o nome de vocês e o meu coração vai ouvir (LISPECTOR, 1983, p. 10).

Há uma outra representação do real para seus personagens na infância. Esta vem impregnada de um nível de consciência que é o mesmo ao que a autora aproxima seu bestiário, o que seria uma espécie de ruptura com o mundo lógico. Nessa diegese, a criança em contato com a realidade, apropria-se dela através de uma representação em que toda a sua potencialidade humana se realiza.

Através da liberdade e da busca pela aprendizagem, Clarice colide contra tabus que ajudam a manter a lógica vigente no mundo estável ao qual ela pretende abalar. Isso se dá sob questionamentos lançados geralmente em símbo- 
los de minorias ou excluídos, como os idosos, as crianças e os animais. A ética é questionada, em seus alicerces, em quem a constrói, em quem a mantém e na motivação de mantê-la.

A obra de Clarice Lispector dá margem à análise da infância sob o prisma de uma identidade metamórfica, independente e consciente em seus textos. Insinua questionamentos das representações do real infantil, comumente expostas nas obras literárias infantis como algo estático e cândido. Aspectos a que se opõe o universo diegético da escritora, materializado nas escolhas temáticas recorrentes, nos questionamentos morais lançados e na linguagem, tudo isso dando margem, através do ato de lembrar/registrar, a uma reinvenção do ser infantil.

Exemplo de outra época, Ziraldo é amostra do que ocorreu com a literatura infantil pelo estreitamento de suas relações com o mercado editorial. Após um grande fomento ocorrido na década de 70, criou-se o profissional específico absorvido pela iniciativa privada incentivada pelo governo. Estavam lançadas as bases para o desenvolvimento do mercado editorial necessárias para torná-lo uma grande potência comercial.

O perfil de Ziraldo como escritor de literatura infantil é curioso por conter em si todos os traços que exigem do autor atual sua mobilização não-literária a partir do literário. A versatilidade do autor ao se desdobrar em diversas funções e cargos a partir de seu papel literário é impressionante e reveladora.

A mobilização não-literária de Ziraldo não é um fato que precise ser questionado, mas há aí algum resíduo do que vem a ser uma das representatividades requeridas para o escritor de literatura infantil moderno.

Quando vemos seu personagem Menino Maluquinho motivando a produção de renda em licenciamentos, entramos na passagem para o panorama atual de plurissignificação extraliterária do literário, em que o sentido inicial (a literatura) passa a ser segundo plano.

A fase mais remota de Ziraldo como autor de histórias infantis enquadrao na fase de desenvolvimento da relação entre mercado editorial e literatura infantil, mas o momento atual do autor já o coloca dentro do quadro último da relação, que é o quadro da defasagem dos signos e dos valores.

Há, hoje em dia, uma forte ligação entre uma hipermídia e o mercado livreiro. Esse quadro traz a questão do caminho da defasagem dos valores que antes revestiam o objeto literário, a saber, o valor de uso, o de troca e o do próprio signo fetichizado. 
A prova dessa transcendência é que o prolongamento não-literário do objeto literário ultrapassa toda a razão de ser da criação literária e reveste-a de um esgotamento de si mesma pela proliferação desenfreada de sua própria permanência onipresente.

Isso quer dizer que o que acontece com obras como as da série Harry Potter, de J. K Rowling, já é reflexo do valor fractal gerado pela atual conjuntura pós-moderna, na qual possuir camisetas, bonés, tênis, cadernos, lápis, assistir aos filmes ou mesmo ter os livros da série já não tem nada ligado ao motivo inicial da literatura: a fruição estética. Pois esse sentido original já está desligado pela superabundância multidirecional irradiada na ubiquidade dispersiva dos signos literários e seus valores.

Cuidadosamente orquestrada pela mídia, a série lançada por J. K. Rowling é uma lição de profissionalismo do hoje tão sofisticado sistema pelo qual circula a literatura infantil. Da identidade da autora cuidadosamente esculpida ao suspense marqueteiro do lançamento de cada volume, do latinório macarrônico às discussões sobre acertos e desacertos éticos e pedagógicos da história, tudo é... literatura! (LAJOLO, 2007, p. 11).

É literatura, mas é literatura fractal. Literatura que se dissemina indefinidamente com seus valores autorreproduzidos infinitamente. Aqui ainda não entra quesitos avaliativos, já que a profusão de valores não nos dá referência nenhuma para um julgamento. É somente uma constatação dos fatos, mera exposição que não pretende nem mesmo entrar no princípio de imanência da obra.

Na saga de Rowling, a vassoura é uma das principais estrelas do mundo mágico. O contexto da Idade Média, do tempo das bruxas perseguidas pela Inquisição, surge atualizado pela linguagem da sociedade de consumo de massas: a vassoura ganha inovações tecnológicas a cada ano, como os automóveis e os aparelhos de televisão; ganha também preços mirabolantes e vira objeto de desejo de crianças e adultos. Para o prosaico objeto, Rowling inventa um catálogo de inovações; existem até agora a antiga versão da Shooting Star, o modelo utilizado pelo amigo pobre de Harry, Rony, capaz de ser ultrapassado no vôo até por borboletas; a Cleansweep Sevens, um pouco menos lenta, utilizada pelo time de Corvinal; o modelo Nimbus 2000, a primeira vassoura adquirida pelo 
herói, com que ele estréia no jogo de quadribol aos 11 anos; a Nimbus 2001, com a qual o inimigo Malfoy tenta ser mais rápido do que Harry, e o fantástico exemplar da Firebolt, presente de Natal, anônimo, que se supunha enfeitiçado e perigoso, mas que, ao final, revela-se um regalo de Sirius, o padrinho foragido [...] (GUTKOSKI, 2005, p. 80)

O ciclo se completa com a ressignificação de signos e valores nas narrativas. Antes, fábulas gritavam violência a um público rude e tosco, segundo alguns olhares. Hoje, o realismo detalhado e a violência na narrativa infantil fazem os contos dos irmãos Grimm parecerem cândidas histórias para crianças.

Com tal comparação, vemos os signos (representação da violência) e os valores (motivação da representação da violência, sua assimilação) sofrerem alteração histórica.

Se um enredo trazia a violência para a trama tinha um objetivo visível: doutrinação pelo medo, ou seja, tinha função moral e ideológica. No momento em que a violência surge nas histórias modernas, vem destituída de intencionalidade profunda e aparece apenas e gratuitamente para uma função superficial de atração para o consumo. Vem esvaziada de sua função primária, o choque, causar medo, pois a irradiação dos signos e valores já banalizou a violência tornando-a corriqueira, sem função.

Quando se cresce em meio à violência seu aparecimento já não causa mais impacto, num mecanismo de defesa psicológico que explica as crianças espancadas que não aprendem com os açoites. Pior do que a violência é o medo da violência; e, quando esse medo é superado pela internalização, assimilação pela banalização da violência, ela já não surte efeito.

O fato do redimensionamento e da irradiação dos valores e dos signos não é uma exclusividade da literatura infantil e muito menos é o total decréscimo da qualidade do objeto literário como arte. Ao contrário, é a assunção da qualidade como função em uma disseminação extrema que atinge em cheio a arte literária, fazendo de sua ascendência algo que não cabe em si e é obrigada ao retorno, a uma implosão, uma involução do valor pela dispersão de suas características até seu desaparecimento, consumindo-se até a última gota de tinta da literatura infantil. 


\section{Referências Bibliográficas}

BAUDRILLARD, Jean. A transparência do mal: ensaios sobre os fenômenos extremos. Trad. Estela dos Santos Abreu. Campinas: Papirus, 2008.

BAUDRILLARD, Jean. O sistema dos objetos. Trad. Zulmira Ribeiro Tavares. São Paulo: Perspectiva, 2007.

BAUMAN, Zygmunt. Globalização: as consequências humanas. Tradução de Marcus Penchel. Rio de Janeiro: Jorge Zahar Editor, 1999.

COHN, Clarice. Antropologia da criança. Rio de Janeiro: Jorge Zahar Editor, 2005.

GUTKOSKI, C. Do pó de pirlimpimpim ao pó de flu: transportes para a fantasia em Monteiro Lobato e J. K. Rowling. In: JACOBY, Sissa; RETTENMAIER, Miguel (Orgs.). Além da plataforma nove e meia. Passo Fundo: UPF, 2005, p. 67-90.

LAJOLO, Marisa. Harry Potter: enfim... o fim! In Suplemento Literário, out/2007, p. 10-11.

LINN, Susan. Crianças do consumo: a infância roubada. Trad. Cristina Tognelli. São Paulo: Instituto Alana, 2006.

LISPECTOR, Clarice. A mulher que matou os peixes. Rio de Janeiro: Nova Fronteira, 1983.

ROCHA. Everardo P. Guimarães. Magia e capitalismo: um estudo antropológico da publicidade. São Paulo: Brasiliense, 1995.

STEINBERG, S. R.; KINCHELOE, J. L. (Org.) Cultura infantil: a construção corporativa da infância. Trad. George E. Japiassú Bricio. Rio de Janeiro: Civilização Brasileira, 2004.

Recebido em 03 de maio e aprovado em 18 de maio de 2011. 